\title{
Using Electron Induced Dissociation (EID) on an LC Time-Scale to Characterize a Mixture of Analogous Small Organic Molecules
}

\author{
Aruna S. Prakash, ${ }^{1}$ Michael J. P. Smith, ${ }^{1}$ Zied Kaabia, ${ }^{1}$ Glenn Hurst, ${ }^{1}$ Ci Yan, ${ }^{1}$ \\ Martin Sims, ${ }^{2}$ Anthony W. T. Bristow, ${ }^{2}$ Peter Stokes, ${ }^{1}$ David Parker, ${ }^{1}$ Jackie A. Mosely ${ }^{1}$ \\ ${ }^{1}$ Department of Chemistry, Durham University, South Road, Durham, DH1 3LE, UK \\ ${ }^{2}$ Analytical Science, Pharmaceutical Development, AstraZeneca, Macclesfield, Cheshire, SK10 2NA, UK
}

\begin{abstract}
LC ESI FTICR MS of a sample of cediranib identified this pharmaceutical target molecule plus an additional 10 compounds of interest, all of which were less than $10 \%$ total ion current (TIC) peak intensity relative to cediranib. LC FTICR tandem mass spectrometry using electron induced dissociation (EID) has been achieved and has proven to be the best way to generate useful product ion information for all of these singly protonated molecules. Cediranib $[\mathrm{M}+\mathrm{H}]^{+}$ fragmented by EID to give 29 product ions whereas QTOF-CID generated only one very intense product ion, and linear ion trap-CID, which generated 10 product ions, but all with poor S/N. Twenty-six of the EID product ions were unique to this fragmentation technique alone. By considering the complementary LC-EID and LC-CID data together, all 10 unknown compounds were structurally characterized and proven to be analogous to cediranib. Of particular importance, EID produced unique product ion information for one of the low level cediranib analogues that enabled full characterization of the molecule such that the presence of an extra propylpyrrolidine group was discovered and proven to be located on the pyrrolidine ring of cediranib, solving an analytical problem that could not be solved by collision induced dissociation (CID). Thus, it has been demonstrated that EID is in harmony with the chromatography duty-cycle and the dynamic concentration range of synthetic compounds containing trace impurities, providing crucial analytical information that cannot be obtained by more traditional methodologies.
\end{abstract}

Key words: Tandem mass spectrometry by electron induced dissociation, Structural characterization of pharmaceuticals, LC MS/MS for low abundant compounds

\section{Introduction}

T iquid chromatography-mass spectrometry (LC-MS) is $\mathcal{L}$ an integral part of drug discovery and development in

Electronic supplementary material The online version of this article (doi:10.1007/s13361-012-0338-6) contains supplementary material, which is available to authorized users.

Correspondence to: Jackie Mosely; e-mail: jackie.mosely@durham.ac.uk the pharmaceutical industry, routinely used to reveal and characterize trace-level impurities, by-products, and degradation products, which are common occurrences in synthetic chemistry reactions [1]. The need to identify all components present alongside a synthetically produced target compound is often hampered by the fact that these undesirable molecules can be structurally similar to the target compound, yet present at much lower concentrations. LC ESI MS/MS has the sensitivity with which to detect molecules at low concentrations and the experimental flexibility to extract 
information that can lead to proposed empirical formulae and molecular structure [2-6]. There are many MS/MS techniques available, the most common one used in the pharmaceutical industry being collision induced dissociation (CID). CID involves collisions between precursor ions and neutral gaseous atoms or molecules, which results in the conversion of a precursor ion's kinetic energy into internal energy. This increase in internal energy causes bond dissociation within the precursor ion, typically favoring the lowest energy fragmentation pathways [7-9]. Problems often arise upon the CID analyses of analogous compounds as product ions observed from the cleavage of the weakest bonds may not allude to the location of, or nature of, such small structural molecular changes, demanding that other analytical approaches be explored. A more recent addition to the tandem MS toolbox is electron capture dissociation (ECD), an electron-based fragmentation technique primarily used to fragment and characterize multiply charged peptide and protein cations [10-12]. It involves the interaction of low energy electrons $(1-5 \mathrm{eV})$ with multiply protonated species, resulting in charge reduction and bond cleavage [13, 14]. ECD of peptides/proteins has been shown to produce a simple but regular distribution of product ions that complement the CID distribution, but the ability of ECD to preserve labile covalently bound modifications gives this technique a distinct advantage over CID [15-18]. In an attempt to gain yet further information regarding peptide structure, Zubarev et al. increased the ECD electron energy beyond what is common for multiply charged peptides $(>10 \mathrm{eV})$, generating hotter electrons [13, 19]. Applying these higher energy electrons to multiply charged peptides is known as hot electron capture dissociation (hECD) and has been shown to produce a significant increase in side chain fragmentation producing an even greater depth of information [20, 21].
More recently, the interaction between hotter electrons and singly charged cations has been shown to induce fragmentation and is referred to as electron induced dissociation (EID) [19, 22-29]. In a very recent study with pharmaceutical type molecules, EID produced extensive product ion data that largely complemented CID, was comparable to electron ionization (EI), and was more tolerant to a wider range of charge carrying species than CID [29].

ECD is somewhat notorious for its lack of efficiency compared with other techniques such as CID [10, 15]. Historically, in order to achieve usable spectra, samples of high concentration were preferred and $\mathrm{S} / \mathrm{N}$ allowed to buildup by accumulating many spectra. Significant inroads have been made in optimizing methodologies to facilitate ECD of peptides on the LC time-scale [3, 4, 30]. For EID to be widely pertinent to real-world applications, it too must be coupled to chromatographic techniques, producing spectra of sufficient quality that information can be gained for compounds of a wide dynamic concentration range from the limited number of spectra achievable across a chromatographic peak. This development will show that LC-EID is achievable, plus it provides unique information not afforded by LC-CID. The power to generate multiple datasets of complementary information on one instrument in the very short LC time-scale facilitates greater in-depth analysis of complex mixtures of small molecules, which are typical of the pharmaceutical industry.

\section{Experimental}

\section{Sample Preparation and Sample Introduction}

The sample of cediranib was supplied by AstraZeneca, Macclesfield, UK. All solvents were purchased from Sigma-

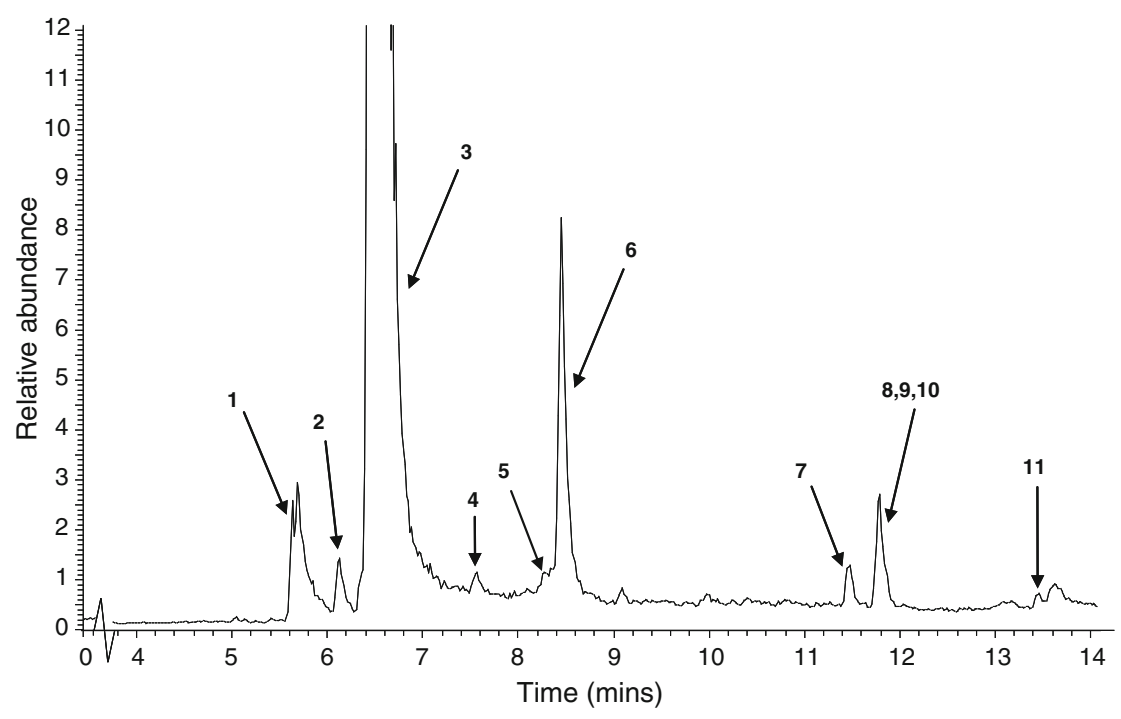

Figure 1. Total Ion Chromatogram (TIC) from LC FTICR MS analysis of cediranib. Peaks labeled $\mathbf{1}$ to $\mathbf{1 1}$ indicate the presence of components proven to be from the cediranib sample. A comparison of sample and control is given in supplementary information Figure S1 
Table 1. Summary of product ions following LC-CID and LC-EID of cediranib labeled LC peak number $\mathbf{3}$ and analogues labeled LC peak number $\mathbf{1}, \mathbf{2}$, and 4-11

\begin{tabular}{|c|c|c|c|c|c|c|}
\hline \multirow{2}{*}{$\begin{array}{l}\text { LC peak } \\
\text { number }\end{array}$} & \multirow{2}{*}{$\begin{array}{l}\text { Observed MS } \\
\text { peak } m / z\end{array}$} & \multirow{2}{*}{$\begin{array}{l}\text { Proposed molecular } \\
\text { formula for }[\mathrm{M}+\mathrm{H}]^{+}\end{array}$} & \multicolumn{2}{|c|}{ Number of product ions observed } & \multirow{2}{*}{$\begin{array}{l}\text { Number of product } \\
\text { ions common between } \\
\text { EID and CID }\end{array}$} & \multirow{2}{*}{$\begin{array}{l}\text { Number of product ions } \\
\text { common between Cediranib } \\
\text { (peak 3) and an analogue }\end{array}$} \\
\hline & & & EID & CID & & \\
\hline 1 & 562 & $\mathrm{C}_{32} \mathrm{H}_{41} \mathrm{O}_{3} \mathrm{~N}_{5} \mathrm{~F}$ & 17 & 15 & 2 & 11 \\
\hline 2 & 899 & $\mathrm{C}_{50} \mathrm{H}_{53} \mathrm{O}_{6} \mathrm{~N}_{8} \mathrm{~F}_{2}$ & 5 & 7 & 2 & 5 \\
\hline 3 & 451 & $\mathrm{C}_{25} \mathrm{H}_{28} \mathrm{O}_{3} \mathrm{~N}_{4} \mathrm{~F}$ & 29 & 10 & 3 & N/A \\
\hline 4 & 788 & $\mathrm{C}_{43} \mathrm{H}_{40} \mathrm{O}_{6} \mathrm{~N}_{7} \mathrm{~F}_{2}$ & 2 & 11 & 1 & 4 \\
\hline 5 & 481 & $\mathrm{C}_{25} \mathrm{H}_{26} \mathrm{O}_{5} \mathrm{~N}_{4} \mathrm{~F}$ & 12 & 5 & 4 & 4 \\
\hline 6 & 340 & $\mathrm{C}_{18} \mathrm{H}_{15} \mathrm{O}_{3} \mathrm{~N}_{3} \mathrm{~F}$ & 21 & 15 & 5 & 9 \\
\hline 7 & 447 & $\mathrm{C}_{25} \mathrm{H}_{24} \mathrm{O}_{3} \mathrm{~N}_{4} \mathrm{~F}$ & 19 & 3 & 3 & 6 \\
\hline 8 & 430 & $\mathrm{C}_{25} \mathrm{H}_{21} \mathrm{O}_{3} \mathrm{~N}_{3} \mathrm{~F}$ & 17 & 21 & 9 & 8 \\
\hline 9 & 339 & $\mathrm{C}_{18} \mathrm{H}_{14} \mathrm{O}_{3} \mathrm{~N}_{3} \mathrm{~F}$ & 17 & 9 & 9 & 6 \\
\hline 10 & 921 & Unknown & 4 & 8 & 3 & 2 \\
\hline 11 & 691 & $\mathrm{C}_{37} \mathrm{H}_{29} \mathrm{O}_{6} \mathrm{~N}_{6} \mathrm{~F}_{2}$ & 2 & 16 & 1 & 4 \\
\hline
\end{tabular}

Aldrich, Dorset, UK. For the chromatography, a solution of cediranib was made to $2 \mathrm{mg} \mathrm{mL}{ }^{-1}$ in methanol; $10 \mu \mathrm{L}$ aliquots were injected on to either a Luna $3 \mu \mathrm{m} \mathrm{C18} \mathrm{(2),}$ $100 \AA, 150 \times 2 \mathrm{~mm}$ column (Phenomenex) with a mobile phase flow rate of $200 \mu \mathrm{L} \mathrm{min}{ }^{-1}$ for a 12 min separation or a 4.5 min separation using a Zorbax SB-C18 $1.8 \mu \mathrm{m} 4.6 \times$ $50 \mathrm{~mm}$ column (Agilent Technologies) with a mobile phase flow rate of $1 \mathrm{~mL} \mathrm{~min}^{-1}$ and a 1:4 split prior to the mass spectrometer. Gradient conditions started at $95 \%\left(\mathrm{H}_{2} \mathrm{O}+\right.$ $0.1 \%$ formic acid $) / 5 \%\left(\mathrm{CH}_{3} \mathrm{CN}+0.1 \%\right.$ formic acid $)$ and finished at $5 \%\left(\mathrm{H}_{2} \mathrm{O}+0.1 \%\right.$ formic acid $) / 95 \%\left(\mathrm{CH}_{3} \mathrm{CN}+0.1\right.$ $\%$ formic acid). A $5 \mu \mathrm{g} \mathrm{mL} \mathrm{m}^{-1}$ solution of cediranib in methanol was used for occasional experiments requiring direct infusion. In such instances a syringe pump delivered the sample solution at a flow rate of $5 \mu \mathrm{L} \mathrm{min}$.

\section{Mass Spectrometry}

Unless stated otherwise, measurements were made using a ThermoFinnigan LTQFT mass spectrometer fitted with a 7 Tesla magnet and equipped with an electrospray ion source (Bremen, Germany). The following ion source parameters were optimized for the most stable ion signal: the nitrogen sheath gas was kept between 8 and 10 arbitrary units, the auxiliary gas and sweep gas were set between 2 and 4 arbitrary units, as per the manufacturer's software, the capillary was heated to $250{ }^{\circ} \mathrm{C}$, and the spray voltage was held at $4-4.5 \mathrm{kV}$. The tube lens voltage was varied to deliver the optimal ion intensity.

Isolation of the precursor ions was carried out in the LTQ ion trap with a fixed isolation window of $4 \mathrm{~m} / \mathrm{z}$ in order to include the full isotopic profile of the compound of interest. All LC-MS/MS experiments were performed by alternating MS and MS/MS scans throughout the chromatographic run. CID experiments were performed entirely within the LTQ ion trap using helium as a collision gas and optimized at a normalised collision energy level of 25 as per the manufacturer's software, unless otherwise stated. EID was performed entirely within the FTICR cell using an indirectly heated dispenser cathode. To generate 'hot' electrons required for EID and hECD, the electron energy was set at 20 arbitrary units, as per the manufacturer's software. The cathode offset was $2.5 \mathrm{~V}$ for LC-MS/MS experiments and $2.1 \mathrm{~V}$ for the direct infusion experiments, resulting in approximate electron energies of 17.5 and $17.9 \mathrm{eV}$, respectively. For ECD, the electron energy was set at 5 arbitrary units, as per the manufacturer's software, and the cathode offset was $2.1 \mathrm{~V}$ resulting in an approximate electron energy of $2.9 \mathrm{eV}$. The electron irradiation time was fixed at $70 \mathrm{~ms}$. Data was recorded using the acquisition software Xcalibur ver. 2.0.7 (Thermo Fisher Scientific Inc.) and processed using the embedded program Qual Browser. Comparative direct infusion ESI QTOF MS measurements were made on a Waters QTOF Premier (Manchester, UK). QTOF-CID experiments were performed using ion source parameters that optimized the precursor ion peak intensity, argon as a collision gas and a collision energy of $25 \mathrm{eV}$.

\section{Results ad Discussion}

\section{LC-MS/MS of Cediranib}

The process for manufacturing cediranib, as with all pharmaceuticals, is rigorously developed and controlled to ensure that any impurities present are well below internationally recognized safety limits. The inherent sensitivity of mass spectrometric methods allows detection of trace level impurities that are below these permitted safe levels. A process development sample of cediranib containing higher

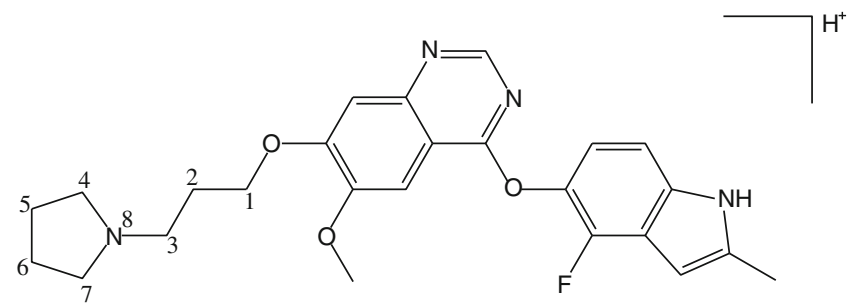

Figure 2. Structure of cediranib with the propylpyrrolidine subunit atoms labeled $\mathrm{C}(1)$ to $\mathrm{C}(7)$ and $\mathrm{N}(8)$ 

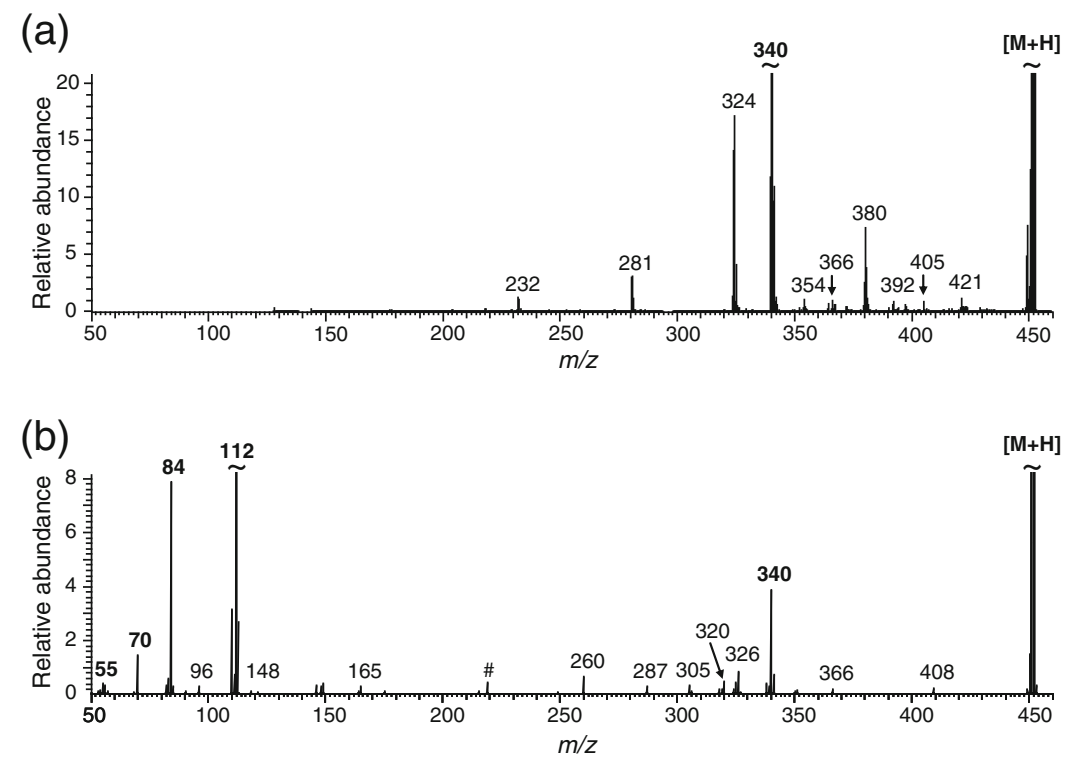

Figure 3. Comparison of tandem MS for protonated cediranib, eluting at 6.55 min (peak 3 in Figure 1), by (a) LC-CID performed on an LTQ ion trap MS (average of 274 scans) and (b) LC-EID performed on an FTICR MS (average of 21 scans). \# Indicates external interference in the FTICR MS and should be discounted. Product ions in bold represent fragmentation relating to the propylpyrrolidine arm

levels of impurities than the marketed compound was analyzed by LC FTICR MS, which separated and detected eleven different compounds of varying ion abundance. Those compounds are labeled $\mathbf{1}$ to $\mathbf{1 1}$ on the total ion chromatogram shown in Figure 1. The most intense peak, 3, relates to a precursor ion at $451.21370 \mathrm{~m} / \mathrm{z}$, which corresponds to the empirical formula $\mathrm{C}_{25} \mathrm{H}_{28} \mathrm{~N}_{4} \mathrm{O}_{3} \mathrm{~F}$ with an accuracy of $0.7 \mathrm{ppm}$ and is taken to be protonated cediranib, as expected. Accurate mass measurements for $\mathbf{1}$, $\mathbf{2}$, and $\mathbf{4}$ to $\mathbf{1 1}$ suggested molecular formulae in each case, as given in Table 1, however molecular structures remained unknown.
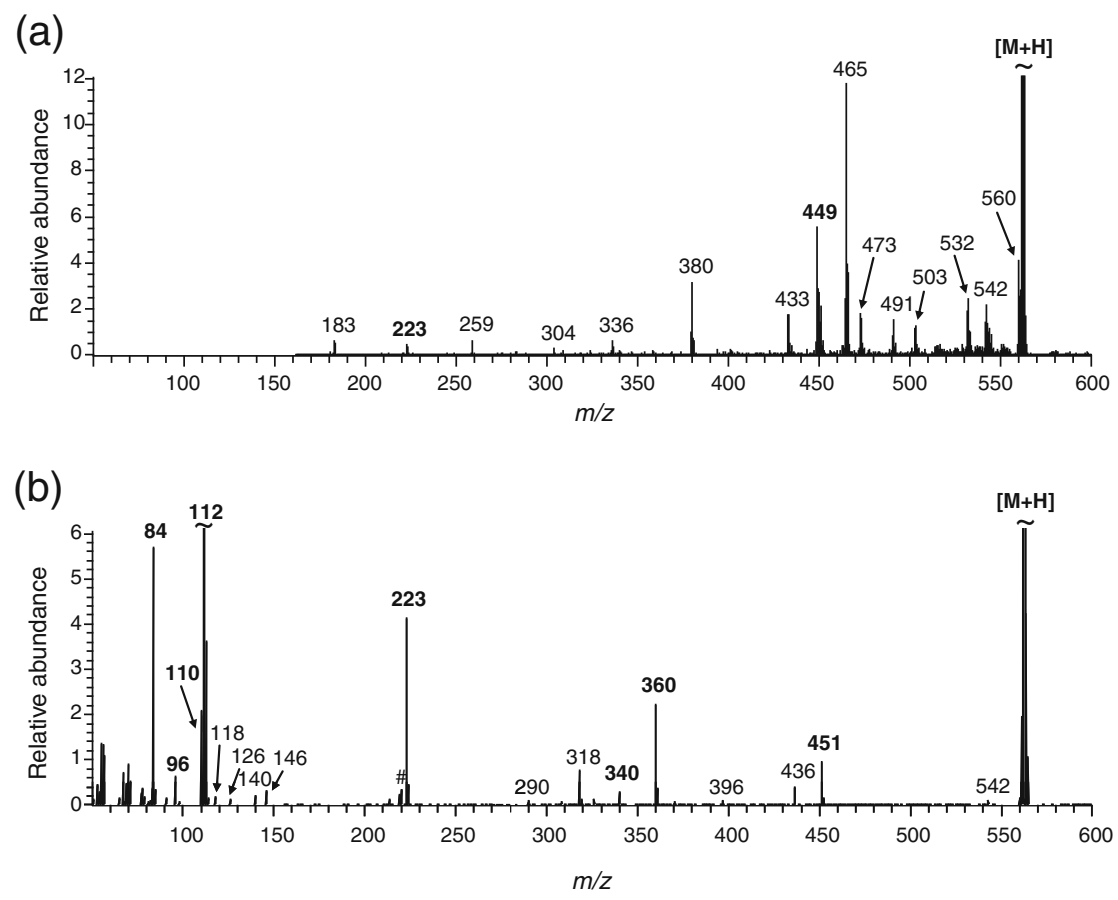

Figure 4. (a) LC-CID (average of 157 scans) and (b) LC-EID (average of 12 scans) of $562 \mathrm{~m} / z$ eluting at 5.69 min, labeled peak 1 in Figure 1. Product ions labeled in bold represent fragmentation relating to the propylpyrrolidine arms, including 223 and $360 \mathrm{~m} / z$, which confirm the location of the modification. \# Indicates external interference in the FTICR MS and should be discounted 
Initial CID experiments to probe the structure of cediranib (Figure 2) were carried out by direct infusion of sample into a QTOF MS. The protonated cediranib molecule fragmented to give only one product ion peak at $112 \mathrm{~m} / z(\mathrm{~S} / \mathrm{N}>30,000 / 1$, data not shown), corresponding to the cleavage of the $\mathrm{C}(1)-\mathrm{O}$ bond of the propylpyrrolidine arm. This provides very little useful information about the molecular structure, highlighting the need for additional analytical techniques. Identification of the unknown species by tandem mass spectrometry was hampered by their low ion abundances, particularly in the presence of such a hugely abundant target compound. Coupling MS with chromatography minimized in-source ion suppression, improving precursor ion $\mathrm{S} / \mathrm{N}$ in preparation for MS/MS. In this instance, both CID and EID have been employed to target and identify the unknown species present in the cediranib sample. Figure 3a shows the spectrum obtained from the LC-CID of cediranib performed and detected in the LTQ of the LTQFT. The single product ion at $112 \mathrm{~m} / z$ that was observed from the QTOF CID is not observed due to the one-third cut-off, which affects MS/MS carried out in quadrupole ion traps [31]. This results in the majority of CID product ions being present in the higher $\mathrm{m} / \mathrm{z}$ region, including $340 \mathrm{~m} / \mathrm{z}$, which corresponds to the neutral loss of the propylpyrrolidine moiety. By comparison, the results from LC-EID shown in Figure $3 b$ display the opposite trend for product ion distribution, providing unique information at the lower $\mathrm{m} / \mathrm{z}$ range. The peak at $112.11208 \mathrm{~m} / \mathrm{z}$ corresponds to the empirical formula $\mathrm{C}_{7} \mathrm{H}_{14} \mathrm{~N}$ with an accuracy of $0.04 \mathrm{ppm}$, confirming the identity of the propylpyrrolidine arm of the molecule. Comparison of LC-CID and LC-EID product ion spectra really highlights the complementary nature of these two techniques, supporting previous studies [29], but also demonstrates that both are achievable in the LC timescale.

\section{LC-MS/MS of Unknown Species}

The first of the unknown species to be studied was the first to elute from the column, peak 1 with a retention time of $5.69 \mathrm{~min}$ (see Figure 1). This relates to a mass peak $562.31897 \mathrm{~m} / \mathrm{z}$, which corresponds to the empirical formula $\mathrm{C}_{32} \mathrm{H}_{41} \mathrm{~N}_{5} \mathrm{O}_{3} \mathrm{~F}$ with an accuracy of $0.3 \mathrm{ppm}$. The LC FTICR MS/MS of this precursor ion is given in Figure 4 for (a) LCCID and (b) LC-EID. Comparison shows the LC-EID data to be the most immediately useful data, despite being a summation of 13 times less spectra than for LC-CID. Accurate mass measurement on the product ion at $451 \mathrm{~m} / \mathrm{z}$ proposed a molecular formula $\mathrm{C}_{25} \mathrm{H}_{28} \mathrm{~N}_{4} \mathrm{O}_{3} \mathrm{~F}$ with an accuracy of $0.1 \mathrm{ppm}$. This is the same empirical formula as protonated cediranib, so at a glance the likely relationship between these two molecules is established. The neutral loss from 562 to $451 \mathrm{~m} / \mathrm{z}$ during EID is consistent with a fragment having the empirical formula $\mathrm{C}_{7} \mathrm{H}_{13} \mathrm{~N}$ and is considered to be most likely due to the addition of a second propylpyrrolidine arm onto the parent molecule during synthesis. Further indication into the structural similarities can be gained by comparing the LC-EID for cediranib shown in Figure $3 b$ directly with the LC-EID of $562 \mathrm{~m} / \mathrm{z}$ in
Figure $4 \mathrm{~b}$. LC-EID of cediranib and the unknown species at $562 \mathrm{~m} / \mathrm{z}$ resulted in the product ions 70,84 , and $112 \mathrm{~m} / \mathrm{z}$ and accurate mass measurements allowed the empirical formulae $\mathrm{C}_{4} \mathrm{H}_{8} \mathrm{~N}, \mathrm{C}_{5} \mathrm{H}_{10} \mathrm{~N}$ and $\mathrm{C}_{7} \mathrm{H}_{14} \mathrm{~N}$ to be assigned, respectively. These three fragments are all from the propylpyrrolidine arm, a conclusion supported by visually comparing Figure $4 \mathrm{~b}$ against EI mass spectral library records for a number of molecules with alkylpyrrolidine functional groups. Also in common is a product ion at $340 \mathrm{~m} / \mathrm{z}$, confirmed by accurate mass measurement despite lower $\mathrm{S} /$ $\mathrm{N}$ in Figure $4 \mathrm{~b}$, which corresponds to the protonated indolphenol structure given in Figure 5a and represents cediranib minus the propylpyrrolidine arm that is such an intense product ion in itself. In total, nine product ions observed in the LC-EID of the unknown compound at 562 $\mathrm{m} / \mathrm{z}$ can be explained by comparison with the LC-EID of protonated cediranib, lending credence to the proposal that both molecules are closely structurally related. Now that the unknown molecule with $[\mathrm{M}+\mathrm{H}]^{+}=562 \mathrm{~m} / \mathrm{z}$ is considered to be related to cediranib, the difference being an additional propylpyrrolidine moiety, the question remains as to the location of the second propylpyrrolidine. There are eight

(a)
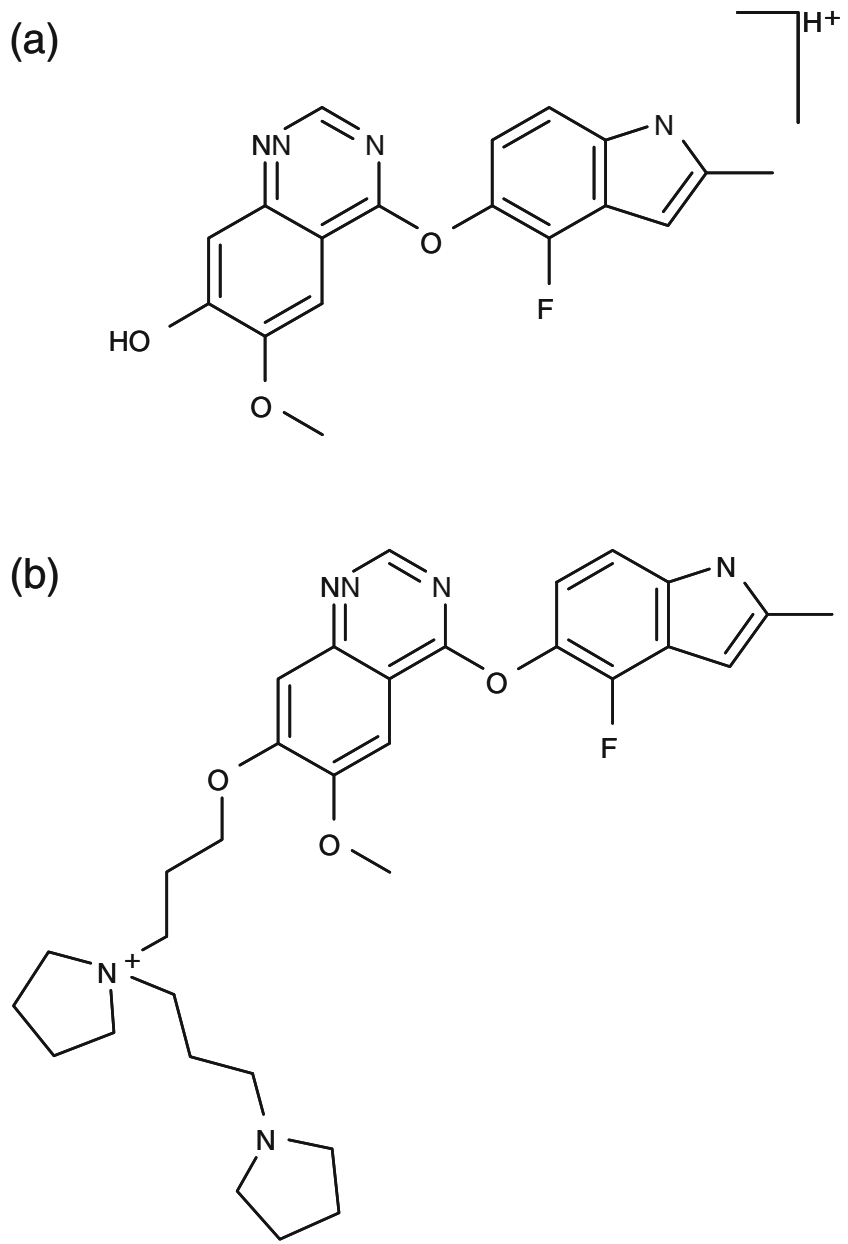

Figure 5. Structures of (a) indolphenol and (b) quaternary ion 
peaks observed in Figure $4 \mathrm{~b}$ for the LC-EID spectrum of $562 \mathrm{~m} / \mathrm{z}$, which are not observed from the LC-EID of protonated cediranib, two of which provide insight to the location of the extra functional group. First, the peak at 223 $\mathrm{m} / \mathrm{z}$ has been determined to have a molecular formula of $\mathrm{C}_{14} \mathrm{H}_{27} \mathrm{~N}_{2}$ (0.7 ppm error), consistent with two propylpyrrolidine arms. As the $\mathrm{C}(1)-\mathrm{O}$ is the main cleavage site within this molecule, this suggests that the addition of the second propylpyrrolidine is situated on one of seven carbon atoms labeled $\mathrm{C}(1)$ to $\mathrm{C}(7)$ or the nitrogen atom $\mathrm{N}(8)$ as described in Figure 2. In fact, evidence for this at very low abundance is also present in the LC-CID spectrum in Figure 4a. Second, the peak at $360 \mathrm{~m} / \mathrm{z}$ has been identified as a fragment with the molecular formula $\mathrm{C}_{21} \mathrm{H}_{18} \mathrm{~N}_{3} \mathrm{O}_{3}$ (1.4 ppm error), which is proposed to correspond to the loss of one intact propylpyrrolidine moiety plus the pyrrolidine ring of the second arm and hydrogen fluoride $\left(\mathrm{C}_{7} \mathrm{H}_{14} \mathrm{~N}_{1}+\mathrm{C}_{4} \mathrm{H}_{8} \mathrm{~N}_{1}+\right.$ $\mathrm{HF})$. This further implies that the addition is located on the pyrrolidine ring $\mathrm{C}(4)-\mathrm{C}(7)$ or $\mathrm{N}(8)$. NMR analysis of the extracted impurity corroborates the MS findings and further identifies the location of the second propylpyrrolidine as the $\mathrm{N}(8)$ atom, giving a quaternary ion as shown in Figure 5b.

The remaining unknown compounds labeled 2, 4-11 in Figure 1 have been investigated using the same LC-CID and LC-EID methodology and results are summarized in Table 1.
Here, the total number of product ions has been counted for each technique (LC-CID and LC-EID). It can clearly be seen that EID provides a usable number of product ions for all the precursor ions studied, and that the number of EID product ions is comparable or often greater than to CID. The most interesting fact here, though, comes from comparing the observed product ion $\mathrm{m} / \mathrm{z}$ values for each technique. There is very little overlap between the observed product ions, highlighting the complementary nature of these two techniques. Delving further shows that when this complementary data is considered as a whole, the number of peaks that each unknown compound has in common with cediranib is sufficiently high to suggest a strong likelihood that each unknown species is chemically related to the cediranib. As with the compound at LC peak 1 (Figure 1), further analytical techniques may be ultimately required to confirm the full molecular structure, however in this case the unknown species labeled 2, 4-11 remain proprietary information of the pharmaceutical company and cannot be discussed further.

\section{Tandem MS of $[\mathrm{M}+2 \mathrm{H}]^{2+}$ for Cediranib}

Cediranib was observed in two charge states: singly and doubly protonated. Doubly charged ions were not observed

(a)
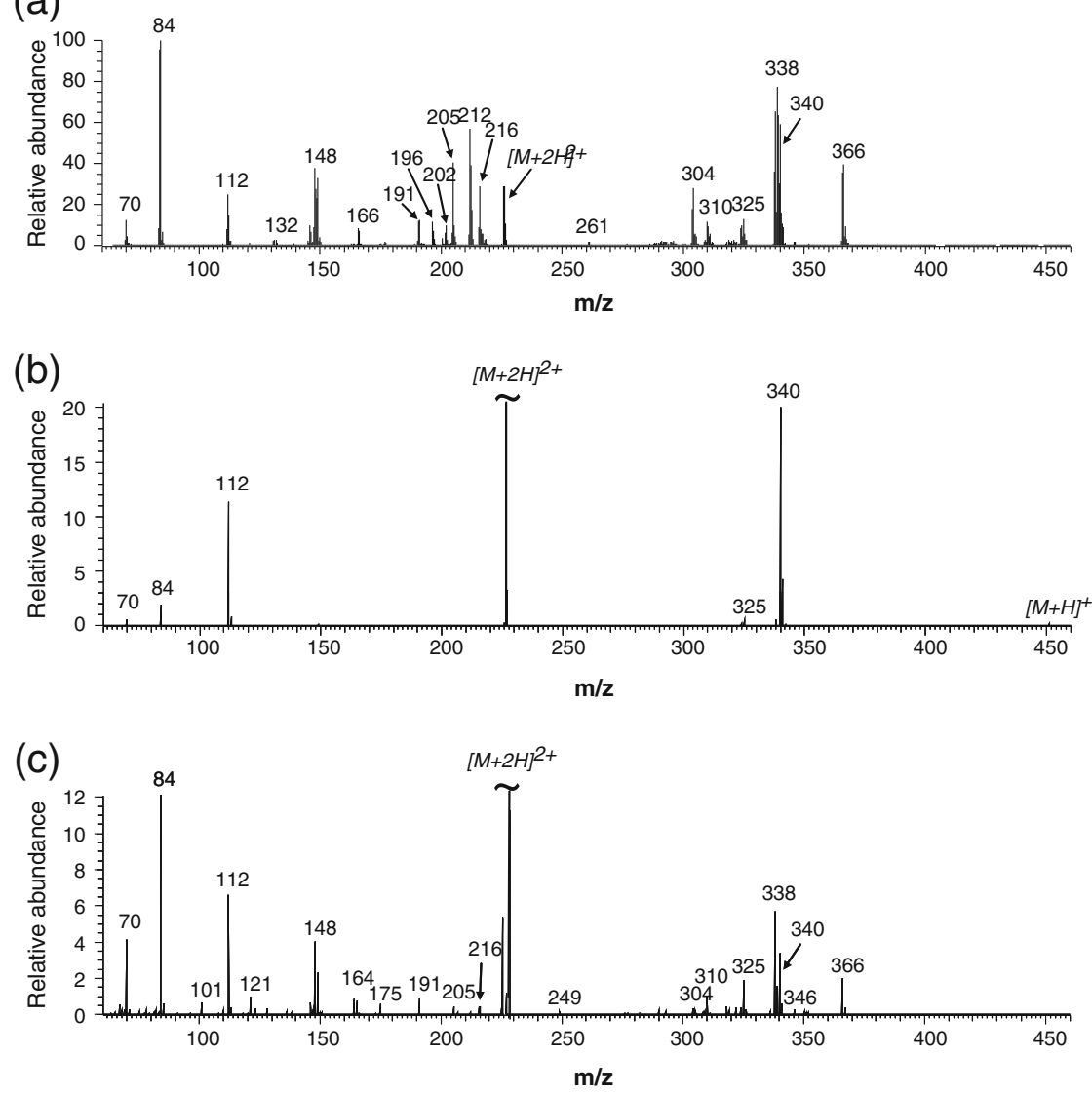

Figure 6. Tandem mass spectrometry of doubly protonated cediranib by direct infusion. Comparison of (a) CID (normalized collision energy of 18) with (b) ECD (electron energy=2.9 eV) and (c) hECD (electron energy=17.9 eV) 
for any of the weakly abundant, co-sprayed cediranib analogues. The doubly protonated adduct of cediranib, despite being considerably less abundant, would tend to be the precursor ion of choice as multiply charged species are generally accepted to provide the superior product ion spectrum [32, 33]. Figure 6a shows CID for $226 \mathrm{~m} / z$, [M+ $2 \mathrm{H}]^{2+}$ for cediranib performed with a normalized collision energy of 18. As could be expected, this spectrum represents a huge improvement over the CID of the singly protonated precursor (Figure 3a) in terms of number of product ions observed and provides comparable data to EID of the singly protonated species (Figure 3b).

As mentioned previously, the interaction between low energy electrons and multiply charged cations is considered to result in the capture of an electron and subsequent bond dissociation, a technique known as electron capture dissociation (ECD). When the ECD approach was employed to study the $[\mathrm{M}+2 \mathrm{H}]^{2+}$ for cediranib (Figure 6b), irradiation with low energy electrons (electron energy $=2.9 \mathrm{eV}$ ) gave very limited information. There is weak evidence of deprotonation from $[\mathrm{M}+2 \mathrm{H}]^{2+}$ to give $[\mathrm{M}+\mathrm{H}]^{+}$but the main dissociation point is cleavage of the $\mathrm{C}(1)-\mathrm{O}$ bond (Figure 2) to create product ions corresponding to protonated indolphenol and the propylpyrrolidine arm. In an experiment akin to $\mathrm{hECD}$, using identical instrumental conditions to the EID experiments, the impact of hotter electrons (electron energy=17.9 eV) was able to induce a much greater degree of dissociation as shown in Figure 6c. This spectrum closely resembles EID of $[\mathrm{M}+\mathrm{H}]^{+}$(Figure $3 \mathrm{~b}$ ) and CID of $[\mathrm{M}+2 \mathrm{H}]^{2+}$ (Figure 6a) in terms of relating product ions to structure. Overall, ECD was of no benefit when characterising this small molecule but hECD of the doubly charged species and EID of the singly charged species are both informative suggesting that the charge state of the precursor ion is not as crucial for the electron based fragmentation techniques.

\section{Conclusion}

The electron energy required to generate the optimum mass spectrum in terms of number of product ions and the $\mathrm{S} / \mathrm{N}$ ratio of the peaks is of the order of $18 \mathrm{eV}$, regardless of whether the molecule is singly or doubly protonated, although if this choice is presented, the doubly protonated precursor ion would be more desirable. Using this value for electron energy, rapid EID has been achieved on the LC timescale and for compounds of a wide dynamic abundance. Perhaps most importantly, LC-EID has proven to be a very powerful tool in that it provided crucial information about the identity and location of a molecular modification to an impurity that would otherwise require preparative isolation and NMR, a time-consuming and expensive alternative. This solution facilitates identification and characterization at a much earlier stage of drug development where sample may be limited.

\section{Acknowledgments}

The authors thank the Durham Mass Spectrometry Group for help and support, AstraZeneca for the donation of the compounds, and the EPSRC for funding.

\section{References}

1. Pan, C., Liu, F., Ji, Q., Wang, W., Drinkwater, D., Vivilecchia, R.: The use of LC/MS, GC/MS, and LC/NMR hyphenated techniques to identify a drug degradation product in pharmaceutical development $J$. Pharmaceut. Biomed. 40, 581-590 (2006)

2. Lee, M.S., Kerns, E.H.: LC/MS applications in drug development Mass Spectrom. Rev. 18, 187-279 (1999)

3. Palmblad, M., Tsybin, Y.O., Ramström, M., Bergquist, J., Håkansson, P.: Liquid chromatography and electron-capture dissociation in Fourier transform ion cyclotron resonance mass spectrometry. Rapid Commun. Mass Spectrom. 16, 988-992 (2002)

4. Creese, A.J., Cooper, H.J.: Liquid chromatography electron capture dissociation tandem mass spectrometry (LC-ECD-MS/MS) versus liquid chromatography collision-induced dissociation tandem mass spectrometry (LC-CID-MS/MS) for the identification of proteins. $J$. Am. Soc. Mass Spectrom. 18, 891-897 (2007)

5. Holcapek, M., Kolarova, L., Nobilis, M.: High-performance liquid chromatography-tandem mass spectrometry in the identification and determination of phase I and phase II drug metabolites. Anal. Bioanal. Chem. 391, 59-78 (2008)

6. Ma, S., Subramanian, R.: Detecting and characterizing reactive metabolites by liquid chromatography/tandem mass spectrometry. $J$. Mass Spectrom. 41, 1121-1139 (2006)

7. Sleno, L., Volmer, D.A.: Ion activation methods for tandem mass spectrometry. J. Mass Spectrom. 39, 1091-1112 (2004)

8. Shukla, A.K., Futrell, J.H.: Tandem mass spectrometry: dissociation of ions by collisional activation. J. Mass Spectrom. 35, 1069-1090 (2000)

9. McLafferty, F.W.: Tandem Mass Spectrometry. Science 214, 280-287 (1981)

10. Zubarev, R.A., Kelleher, N.L., McLafferty, F.W.: Electron capture dissociation of multiply charged protein cations: A nonergodic process. J. Am. Chem. Soc. 120, 3265-3266 (1998)

11. Bakhtiar, R., Guan, Z.Q.: Electron capture dissociation mass spectrometry in characterization of peptides and proteins Biotechnol. Lett. 28, 1047-1059 (2006)

12. Zubarev, R.A.: Reactions of polypeptide ions with electrons in the gas phase. Mass Spectrom. Rev. 22, 57-77 (2003)

13. Zubarev, R.A., Haselmann, K.F., Budnik, B., Kjeldsen, F., Jensen, F.: Towards an understanding of the mechanism of electron-capture dissociation: a historical perspective and modern ideas. Eur. J. Mass Spectrom. 8, 337-349 (2002)

14. Syrstad, E.A., Turecek, F.: Toward a general mechanism of electron capture dissociation. J. Am. Soc. Mass Spectrom. 16, 208-224 (2005)

15. Cooper, H.J., Håkansson, K., Marshall, A.G.: The role of electron capture dissociation in biomolecular analysis. Mass Spectrom. Rev. 24, 201-222 (2005)

16. Zubarev, R.A., Horn, D.M., Fridriksson, E.K., Kelleher, N.L., Kruger, N.A., Lewis, M.A., Carpenter, B.K., McLafferty, F.W.: Electron capture dissociation for structural characterization of multiply charged protein cations. Anal. Chem. 72, 563-573 (2000)

17. Polfer, N.C., Haselmann, K.F., Zubarev, R.A., Langridge-Smith, P.R. R.: Electron capture dissociation of polypeptides using a 3 Tesla Fourier transform ion cyclotron resonance mass spectrometer. Rapid Commun. Mass Spectrom. 16, 936-943 (2002)

18. Mosely, J.A., Murray, B.S., Parker, D.: Electron-capture dissociation and collision-induced dissociation of lanthanide metal-ligand complexes and lanthanide metal-ligand complexes bound to phosphopeptides. Eur. J. Mass Spectrom. 15, 145-155 (2009)

19. Lioe, H., O'Hair, R.A.J.: Comparison of collision-induced dissociation and electron-induced dissociation of singly protonated aromatic amino acids, cysteine and related simple peptides using a hybrid linear ion trap-FT-ICR mass spectrometer. Anal. Bioanal. Chem. 389, 1429-1437 (2007)

20. Kjeldsen, F., Haselmann, K.F., Budnik, B.A., Jensen, F., Zubarev, R. A.: Dissociative capture of hot $(3-13 \mathrm{eV})$ electrons by polypeptide 
polycations: an efficient process accompanied by secondary fragmentation. Chem. Phys. Lett. 356, 201-206 (2002)

21. Cooper, H.J., Hudgins, R.R., Håkansson, K., Marshall, A.G.: Secondary fragmentation of linear peptides in electron capture dissociation. Int. J. Mass Spectrom. 228, 723-728 (2003)

22. Ly, T., Yin, S., Loo, J.A., Julian, R.R.: Electron-induced dissociation of protonated peptides yields backbone fragmentation consistent with a hydrogen-deficient radical. Rapid Commun. Mass Spectrom. 23, 20992101 (2009)

23. Kaczorowska, M.A., Cooper, H.J.: Electron induced dissociation: a mass spectrometry technique for the structural analysis of trinuclear oxo-centred carboxylate-bridged iron complexes. J. Am. Soc. Mass Spectrom. 21, 1398-1403 (2010)

24. Budnik, B.A., Haselmann, K.F., Elkin, Y.N., Gorbach, V.I., Zubarev, R.A.: Applications of electron-ion dissociation reactions for analysis of polycationic chitooligosaccharides in Fourier transform mass spectrometry. Anal. Chem. 75, 5994-6001 (2003)

25. Feketeová, L., Wong, M.W., O'Hair, R.A.J.: The role of metal cation in electron-induced dissociation of tryptophan. Eur. Phys. J. D 60, 11-20 (2010)

26. Yoo, H.J., Håkansson, K.: Determination of double bond location in fatty acids by manganese adduction and electron induced dissociation. Anal. Chem. 82, 6940-6946 (2010)
27. Budnik, B.A., Zubarev, R.A.: $\mathrm{MH}^{2+\bullet}$ ion production from protonated polypeptides by electron impact: observation and determination of ionization energies and a cross-section. Chem. Phys. Lett. 316, 19-23 (2000)

28. Sargaeva, N.P., Lin, C., O'Connor, P.B.: Identification of aspartic and isoaspartic acid residues in amyloid $\beta$ peptides, including $A \beta 1-42$, using electron-ion reactions. Anal. Chem. 81, 9778-9786 (2009)

29. Mosely, J.A., Smith, M.J.P., Prakash, A.S., Sims, M., Bristow, A.W.T.: Electron-induced dissociation of singly charged organic cations as a tool for structural characterization of pharmaceutical type molecules. Anal. Chem. (2011). doi:10.1021/ac200045n

30. Creese, A.J., Cooper, H.J.: The effect of phosphorylation on the electron capture dissociation of peptide ions. J. Am. Soc. Mass Spectrom. 19, 1263-1274 (2008)

31. March, R.E.: An introduction to quadrupole ion trap mass spectrometry. J. Mass Spectrom. 32, 351-369 (1997)

32. Smith, R.D., Loo, J.A., Edmonds, C.G., Barinaga, C.J., Udseth, H.R.: New developments in biochemical mass spectrometry: electrospray ionization. Anal. Chem. 62, 882-899 (1990)

33. Loo, J.A., Edmonds, C.G., Smith, R.D.: Tandem mass spectrometry of very large molecules: serum albumin sequence information from multiply charged ions formed by electrospray ionization. Anal. Chem. 63, 2488-2499 (1991) 